W A R Z A W 1988

Bogdan Horodyski, Krzysztof Kossobudzki, Andrzej Musiał

\title{
THE USE OF PANORAMIC GROUND-PHOTOGRAPHS IN GEOMORPHOLOGIC MAPPINGS OF POLAR REGIONS. EXAMPLE FROM WEST SPITSBERGEN
}

Geomorphological mapping of polar regions comprises, in principle, two types of work. The first are large-scale geomorphological photos $(1: 5,000-1: 10,000)$ of relatively small areas, e.g. of marginal glacier zones, which, repeated periodically afford data for the evaluation of the dynamism of contemporary relief-forming processes. In this work air and ground photogrammetry is used on the basis of which we prepare a large -scale, contour topographical base as a groundwork for proper topical mapping. The photographs are used here mainly as a base for drawing a topographic map of an area, on which the results of geomorphological fieldwork are plotted.

The other group consists of medium-scale works $(1: 25,000-1: 50,000)$. They serve as a geomorphological interpretation of an area and can constitute the base of a map on the scale of 1:50,000-1:100,000. The existing topographical maps, on a scale adapted to the needs of fieldwork, are the base of this work.

The same procedure is obligatory in both types of work. We must determine the scale of field mapping, its extent, its range, topographic base materials and the technique of fieldwork. The range of work usually means: the identification of the geological structure, the genetic classification of relief forms, the determination of their extent and their age. The technique of fieldwork comprises: reconnaissance, sketches, a draft legend, graphic materials, technique of complementary measurements etc. At last, the final scale is determined, e.g. the scale of print, and the degree of generalization.

Such classical mapping is usually facilitated by the use of various types of photographs. In principle, we may distinguish two groups of photographs.

The first group comprises vertical and oblique aerial photographs. Beside their obvious importance in photogrammetric work, they also play a certain role in geomorphological mapping. Vertical photos - single or 
stereoscopic - owing to their generalizing quality are valuable in geomorphological analysis of an area, in the identification and recognition of landforms as well as in the determination of their extent, which is favoured by the constant scale of photographs. However, to exploit them properly, it is necessary to elaborate an adequate interpretative key.

In mountainous regions, where the gradient' of slopes is particularly steep (e.g. Spitsbergen), the advantage of fixing the exact extent of landforms is diminished by the smaller discernibility of slope forms on steep mountain sides due to foreshortening of their surface. When the gradient is $45^{\circ}$, the foreshortening reaches $30 \%$ of the slope length.

Oblique aerial photos are less useful in fixing the extent of landforms. Foreshortening, due to the varying scale of the photograph, causes the necessity of additional measurements. However, the good exposure of mountain slopes in polar areas, by a relatively low light, creates additional possibilities of geomorphological interpretation of farms of small relative altitudes. In the first place it concerns linear forms (faults, edges, knickpoints, etc.) which are hardly visible immediately in the terrain. The weak point of such photos is the highly accidental character of ranging over an area and their, so to say, one-way function, due to which the opposite slopes are invisible during a particular flight.

The second group comprises panoramic ground photos. If they are taken in mountainous regions from peaks, from good view-points, culminations or reverse slopes practically in all directions, they have the same importance in definite geomorphological fieldwork as oblique aerial photos. When obtaining vertical or oblique aerial photos is impossible or too expensive, ground panoramic photography acquires a particular meaning. The field group can do it unaided, by means of rather simple equipment (e.g. a phototheodolite), in a single or stereoscopic version. By combining classical geomorphological field mapping of mountainous areas with the interpretation of such photographs the quality and rate of fieldwork can be substantially improved.

During the Academic Polar Expedition "Spitsbergen '85" geomorphological mapping was done in the western part of Nordenskiöld Land (West Spitsbergen). The field maps were drawn on the scale of $1: 25,000$ on a base obtained through magnification of a Norwegian topographic map, $1: 100,000 .^{1}$ The scale of $1,75,000$ was assumed as scale of destination.

Since it was impossible to obtain aerial photos, the mapped area was covered with a series of panoramic ground photos executed on glass plates by means of a phototheodolite (PHOTO-THEO produced in East Germany) from particularly elevated and exposed points. Fig. 1 presents an example of such a photograph directed eastward, taken from the peak

1 Topografisk Kart aver Svalbard 1:100.000. Blad B 10 Van Mijenfjorden Norges Svalbard - og Ishavs-undersökelser 1948. 


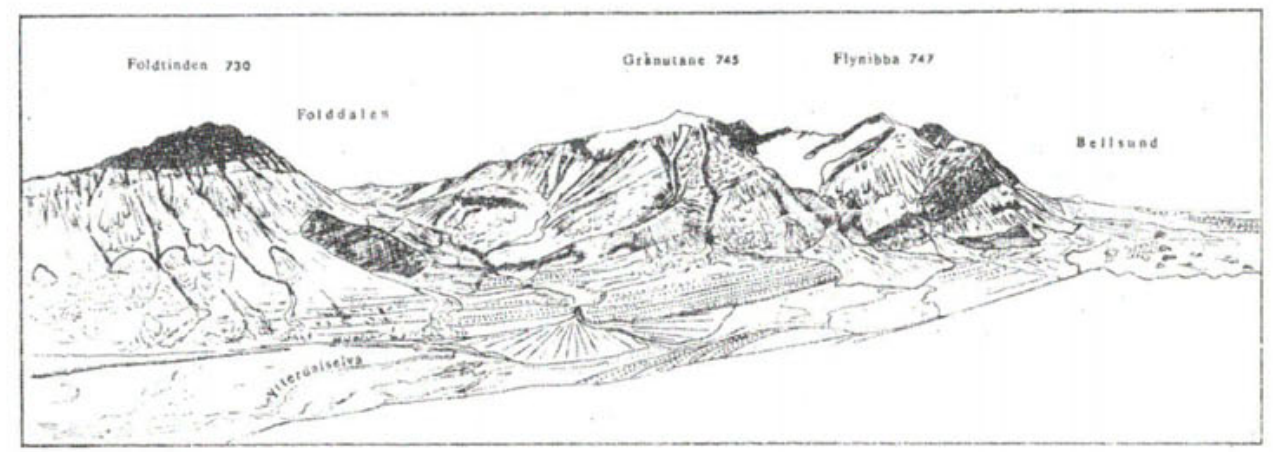

Fig. 1. Drawing from a panoramic ground photograph of the Ytter valley southern part.

Ytterdalssata-593 m above sea level - which locks the Ytter valley from the South (northern border of Bellsund). For technical reasons the original photograph has been replaced in the present paper by its hachured version with a geomorphological interpretation of selected forms (sea terraces, talus cones). The results of geomorphological mapping carried out in the classical way were confronted with the geomorphological interpretation of the photograph. This allowed to find out some forms not noticed in direct mapping or to correct landform extents already marked on the map.

During field investigations the genetic identification of knickpoints running at the slope base of elevations which frame the Ytter valley (Fig. 2) was difficult. The relative altitude of those forms reaches $4-6 \mathrm{~m}$. They occur in several superposed levels. They are almost completely covered with decomposed rock gravitationaly transferred down the slopes, which makes difficult their legibility on aerial vertical photos. The situation of those knickpoints running conformably to the strike of strata suggested their erosive origin because of the varied resistance of the material to weathering.

The geomorphological analysis carried out using panoramic photos has shown explicitly the connection of the forms described above with wave-built terraces. They are a natural prolongation of horizons of sea accumulation into the valley.

The occurrence of those knickpoints in the Ytter valley, which is bordered on both sides with steep and high mountain ridges, suggests that in a recent geological past a fiord existed in this place. Pebbles and sand terraces did not form along its eastern slope, as at the mouth of the Fold valley, owing to lithological conditions (outcropping beds of limestones, dolomites and gypsum). So, the above-described knickpoints are old cliffs corresponding with the successive stages of changes in the coastline of the Greenland Sea.

Panoramic photographs were also useful in distinguishing marine terrace levels. In the analysed part of West Spitsbergen, marine terraces can be noticed, built of variously-grained sands in the top of which there occur 

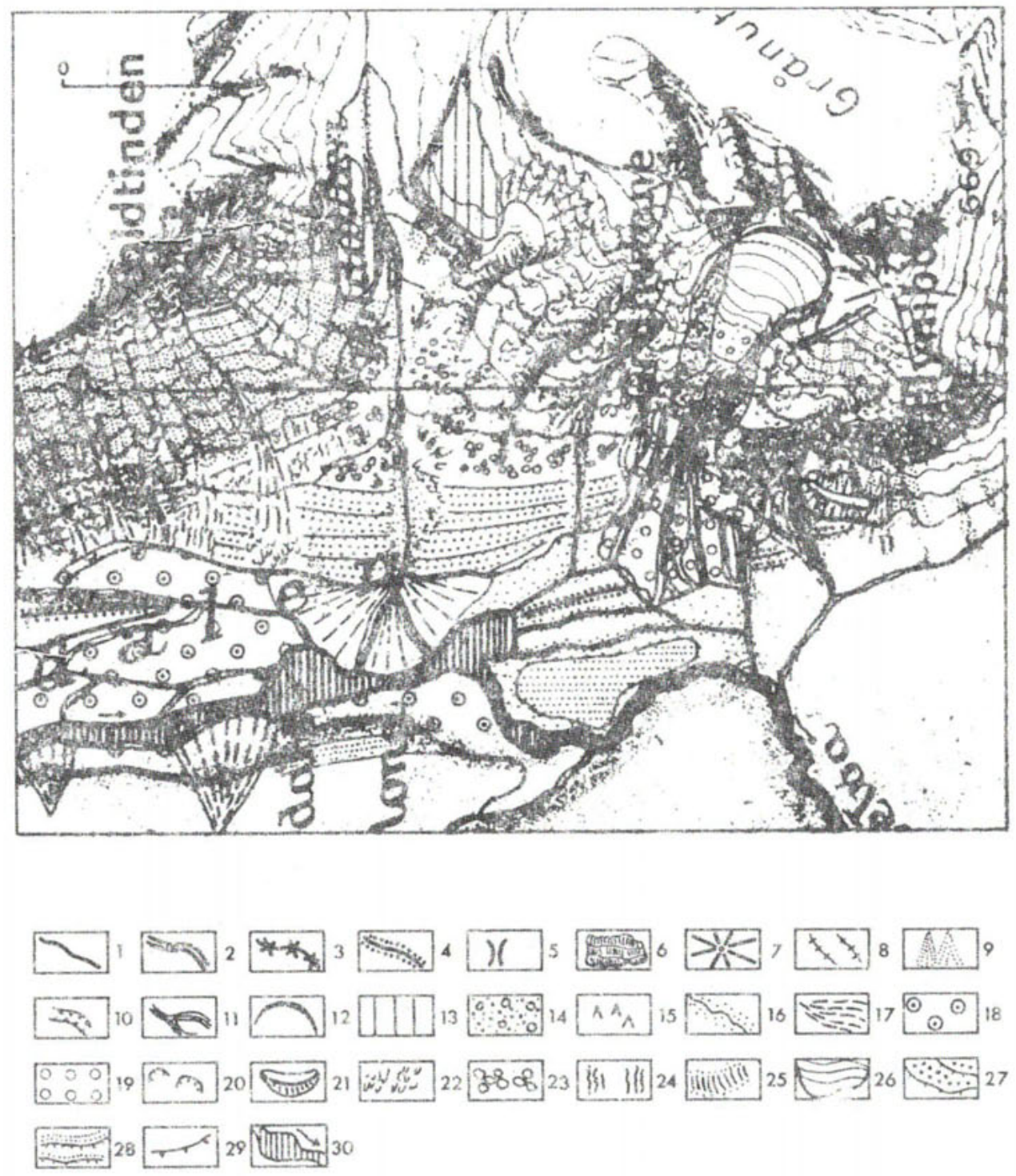

Fig. 2. Geomorphological sketch of the Ytter valley southern part (West Spitsbergen). Eastward orientation conformable with the direction of the photograph.

1 - Sharp ridges and mountain slopes covered with waste mantle, 2 - rounded ridges and mountain slopes with waste mantle, 3 - monadnock ridges and hummocks built of dolerites, 4 -- monadnock ridges and hummocks built of quartzite sandstones, 5 -- passes, 6 - rock walls, 7 -- peaks within ridge plateaux, 8 - gullies, 9 - taluses, 10 - river gaps, 11 incision of river channels, 12 - kars, 13 - fragments of glacial river bottom, 14 - ramparts of terminal and marginal moraines with ice core, $15 \ldots$ ablation cones and hills in zone of terminal and marginal moraines, 16 - valley bottoms, 17 -- alluvial cones, 18 -- outwash plains, 19 - outwash cones, 20 -- nival recesses, 21 - underslope ramparts of nival moraines, 22 -... tongues of solifluction, 23 - fields of stony polygons, 24 - fields of stony strips and streaks, 25 -- old snow patches. 26 -.- glaciers, 27 -- marine terraces built of quartzite sandstone pebbles, 28 - marine terraces built of sand, $29 \ldots$ dead cliffs, 30 - rivers. 
pebbles of carboniferous light quartzite sandstones; they form a characteristic "pavement". At the base of such levels, in small depressions tundra vegetation is growing; on photographs it appears as dark streaks and lines. They are easily seen owing to the dark phototone which facilitates the exact distinction of the particular terraces.

Ground panoramic photos are irreplaceable, especially in the morphologic study of vertical rock walls whicin are fully visible by such exposure. It facilitates the location and identification of: gullies, clints, pinnacles, rock towers, avalanche tracks and taluses. Disturbances of the rock strata system, e.g. faults, folds, etc, are also visible, which supplies additional information in geomorphiological investigations.

Ground panoramic photographs misrepresent the morphology of flat surfaces, e.g. valley bottoms, outwash plains, deltas, which are often photographed in great foreshortening so that small "flat" object, e.g. rims, polygons and stony streaks are invisible on the photo.

The use of panoramic ground photos in the investigations of the relief of Nordenskiöld Land has contributed to a precise and accelerated geomorhologic interpretation of the mapped area. It seems to have a particularly practical significance in polar investigations concerning the geomorphology of mountain regions. Such work has, as a rule, the character of an expedition and can be carried out only during the short summer season. Panoramic ground photographs, single or stereoscopic, are records of pictures observed in the terrain by the geomorphologist and may have the value of a document which will enable him to "inspect" the terrain again during the post-season study work. 
